\title{
Treatment of Experimental Status Epilepticus in Immature Rats: Dissociation Between Anticonvulsant and Antiepileptogenic Effects
}

\author{
LUCIE SUCHOMELOVA, ROGER A. BALDWIN, HANA KUBOVA, KERRY W. THOMPSON, RAMAN SANKAR, AND
} CLAUDE G. WASTERLAIN

\begin{abstract}
Departments of Neurology [L.S., K.W.T., R.S., C.G.W.], and Pediatrics [R.S.], David Geffen School of Medicine, University of California, Los Angeles, CA 90095; Veteran's Administration Greater Los Angeles Healthcare System [L.S., R.A.B., K.W.T., C.G.W.], Los Angeles, CA 90073; Institute of Physiology [L.S., H.K.], Academy of Sciences of the Czech Republic, Prague 142 20, Czech Republic
\end{abstract}

\begin{abstract}
We studied the effects of treating status epilepticus (SE) induced by lithium and pilocarpine at postnatal day 15 (P15) or 28 (P28), on the severity of acute SE and of SE-induced epileptogenesis. Rats received topiramate $(10$ or $50 \mathrm{mg} / \mathrm{kg}$, IP) or diazepam ( $5 \mathrm{mg} / \mathrm{kg}$, IP) 20,40 or $70 \mathrm{~min}$ after pilocarpine, and three months after SE 24-h video/EEG recordings were obtained for one (P28) or two weeks (P15) continuously.

In P15 rats, topiramate did not modify the course of SE, yet treatment at 20 or 40 min completely prevented the development of spontaneous recurrent seizures (SRS) while later treatment (70 min) was partially effective in reducing the severity and frequency of SRS. Diazepam was effective against acute SE at all time points tested. Early (20 min) but not late treatment with diazepam had the effect of reducing the frequency and severity of SRS.

In P28 rats, both drugs reduced the cumulative seizure time. Early treatment $(20 \mathrm{~min})$ with either drug reduced the incidence of chronic epilepsy. Late treatment (40/70 $\mathrm{min}$ ) did not alter the incidence of SRS, but decreased their frequency. This study demonstrates that, in the treatment of SE, anticonvulsant and antiepileptogenic effects can be dissociated in a development-specific manner: topiramate was antiepileptogenic without being an effective anticonvulsant in P15 animals at the doses tested. Diazepam, on the other hand, was a better anticonvulsant than antiepileptogenic agent in the P15 animals at the dose tested. Such effects were not seen in the older animals. (Pediatr Res 59: 237-243, 2006)
\end{abstract}

Q tatus epilepticus (SE) is a frequent neurologic emergency. $\checkmark$ SE is common in infants and toddlers, with more than $50 \%$ of cases of SE occurring under the age of $2 \mathrm{y}(1,2)$.

$\mathrm{SE}$ is associated with an increased risk of developing epilepsy. $30 \%$ of children presenting with SE were found to develop epilepsy subsequently (3). More recently, $41 \%$ of patients with acute symptomatic SE (one-third were children) developed epilepsy within the next 10 y (4).

Received May 10, 2005; accepted August 8, 2005.

Correspondence: Lucie Suchomelova, Ph.D., Veterans Administrations Greater Los Angeles Healthcare System and University of California at Los Angeles, Neurology Research (151), 11301 Wilshire Blvd., Bldg. 114, Rm. 139, Los Angeles, CA 90073, USA; e-mail: 1suchome@ucla.edu

This study was supported by a grant from Johnson and Johnson's Pharmaceutical Research Institute, by VHA Research Service, by a Fellowship of ILAE (L.S.), and bipy research grant NS13515 from NINDS (C.G.W.). Dr Sankar is supported by grants form the NIH, NINDS NS046516 and NS045911. He is also grateful for support from the DAPA Foundation.

DOI: 10.1203/01.pdr.0000196333.16608.30
SE-induced epileptogenesis is common in adult animals, and there is considerable experimental evidence for its occurrence in the immature brain(5-9).

Clinical selection of anticonvulsants has traditionally been based on their ability to block the expression of seizures, but the recent availability of antiepileptic drugs (AEDs) that target many novel molecular targets (10) has generated interest in studying their potential to be antiepileptogenic (e.g., reduce the incidence of epilepsy) or disease-modifying (e.g., reduce the severity of epilepsy). Limited attempts have been made to investigate the antiepileptogenic potential of existing anticonvulsants. Chronic treatment of humans with phenytoin or valproic acid to prevent post-traumatic epilepsy was not successful $(11,12)$. Although several animal studies used chronic drug treatment during the latent period after SE to prevent development of epilepsy, few had positive results (13-16) On the other hand, acute treatment of SE in adult rats can sometimes prevent chronic epilepsy or reduce its severity (16-19), but the effect of anticonvulsants on epileptogenesis has not been studied in immature animals.

We tested the effectiveness of topiramate or diazepam in the acute treatment of lithium/pilocarpine SE at two distinct stages of rat brain development: postnatal day 15 (P15) and postnatal day 28 (P28). These ages roughly correspond to human infancy and prepubescent childhood, respectively (20). We tested the effect of acute treatment on both short-term (severity of SE) and long-term functional outcome (antiepileptogenic or disease-modifying effect).

\section{METHODS}

Animals. Male Wistar albino rats (Simonsen Lab, Gilroy, CA), 15 or $28 \mathrm{~d}$ old (P15 and P28), were used. The day of birth was considered as day 0. Pups were weaned at P21.

All animals were housed in a temperature- and humidity-controlled room with $12 \mathrm{~h}$ light- dark cycles (light cycle starts at $7 \mathrm{AM}$ ) and had free access to food and water. All experiments were conducted with the approval and in accordance with the regulations of the Institutional Animal Care and Use Committee of West Los Angeles VA Medical Center.

Implantation of electrodes. The animals were anesthetized with halothane. A tripolar electrode was then connected to skull screws (the first two were

Abbreviations: P15, P28, postnatal day 15 or 28; SE, status epilepticus; SRS, spontaneous recurrent seizures 
inserted into the skull above right and left frontal cortex, the third one was placed over the cerebellum) and anchored with dental cement. The first two leads recorded the EEG across the hemispheres; the third was used as a ground. After surgery, animals were placed in an observation chamber on a temperature pad until they recovered. P15 rat pups, after recovery, were returned to their mother.

Induction of SE and administration of vehicle: diazepam or topiramate and/or atropine. Lithium $(3 \mathrm{mEq} / \mathrm{kg})$ was administered intraperitoneally on the day of surgery and, $20 \mathrm{~h}$ later, SE was induced with s.c. pilocarpine (60 $\mathrm{mg} / \mathrm{kg}$ ). The pilocarpine dose was established by Sankar (5) for the age groups used in our study. Onset of first ictal activity and continuous polyspike activity were measured. The control group was treated at $70 \mathrm{~min}$ after pilocarpine with vehicle and atropine in amounts sufficient to block most effects of pilocarpine $(10 \mathrm{mg} / \mathrm{kg})$. As a result, if treatment was effective, the original cholinomimetic that resulted in the induction of SE was no longer able to restart seizures. In the other groups, topiramate $(10$ or $50 \mathrm{mg} / \mathrm{kg}$, dissolved in $10 \%$ of DMSO) or diazepam $(5 \mathrm{mg} / \mathrm{kg}$ ) was given intraperitoneally together with atropine sulfate $(10 \mathrm{mg} / \mathrm{kg}), 20,40$ or $70 \mathrm{~min}$ after pilocarpine. Atropine dissolved in DMSO or saline had similar effects on the severity of SE; so these two groups were pooled. The "no SE" control group received only lithium and vehicle. All animals were rehydrated with saline approximately $5 \mathrm{~h}$ after SE (10\% of body weight, s.c.). The body weight was checked daily for $10 \mathrm{~d}$ after SE.

Acute video-EEG monitoring. EEG electrodes were connected to tethered cables with swivel mounts (Plastic One, Roanoke, VA), which fed the amplified signal to a monitoring and recording system (Harmonie Software, Stellate System, Montreal, Quebec, Canada). We used a video-EEG system for $24 \mathrm{~h}$ of continuous monitoring. This system identified seizures and $1 \mathrm{~min}$ of recording before and after each seizure. Each software-recognized seizure was reviewed manually, including time-locked video, to eliminate false positives. We recorded baseline EEG, starting $15 \mathrm{~min}$ before pilocarpine administration. The severity of SE was assessed by measuring the following parameters: latency to seizure interruption (timed from the end of the topiramate, diazepam and/or atropine injection when continuous polyspike or spike and wave activity was interrupted for at least $1 \mathrm{~min}$ ), cumulative seizure time (timed from the topiramate, diazepam and/or atropine injection, subtracting interictal time), number of seizures, duration of SE (time from the onset of SE to the end of the last seizure, including interictal time), total seizure time (total time spent in seizures, timed from the onset of SE, subtracting interictal time), and spike frequency (spikes per hour), using Harmonie Software. Seizures are defined by the software as a discharge lasting at least $3 \mathrm{~s}$, with a mean frequency higher than $3 \mathrm{~Hz}$, coefficient of variation $\geq 65$, and amplitude 2.7 times higher than baseline. For spike detection, the amplitude threshold was set at 4 times baseline. We also evaluated the behavioral correlates of seizures and the effect of treatments on severity of seizures.

We used modified scale from Haas (21): 0) behavioral arrest; 1) mouth clonus; 2) head bobbing; 3) head clonus), 4) bilateral forelimbs clonus; 5) clonus with rearing and falling; 6) wild running and jumping with vocalization; 7) tonus.

Chronic video-EEG monitoring. Separate group of animals undergoing $\mathrm{SE}$ at $\mathrm{P} 15$ or P28, without surgery, were anesthetized 3 mo later with ketamine $(60 \mathrm{mg} / \mathrm{kg}, \mathrm{IP})$ and xylazine $(15 \mathrm{mg} / \mathrm{kg}, \mathrm{IP})$ and implanted with magnetically activated implants for transmitting EEG signals (Data Science International). The implant's cables were connected to skull screws placed over the left frontal and occipital cortex, and anchored with dental cement. After one week of postoperative recovery, the animals were monitored with video-EEG for one (P28) or two weeks (P15) continuously. Each computer-recognized seizure was reviewed manually. The number of spontaneous recurrent seizures (SRS), mean seizure duration and number of spikes, averaged over the one week of continuous recording, were counted using Harmonie Software. The parameters for seizures and spike detection were the same as in acute experiments. Behavioral motor seizure activity was classified according to slightly modified Racine scale (22): 0) electrographic seizure without any detectable behavioral manifestation; 1) face clonus; 2) head nodding; 3) forelimb clonus; 4) forelimb clonus and rearing; 5) forelimb clonus with rearing and falling. We classified behavioral seizures in two categories: 1) Nonconvulsive seizures (scores 0-2), or 2) Convulsive seizures (score 3-5).

Statistical analysis. Each group for acute experiments consisted of at least five animals, and for chronic experiments each group consisted of at least six animals. For acute experiments, statistical comparisons were made using analysis of variance for multiple comparisons with Bonferroni post hoc test for parametric and Dunn's post hoc test for nonparametric data. Planned comparisons with Bonferroni correction, and correlations were used for chronic data. All tests were made using statistical software (Sigmastat, Jandel Scientific). $P$-values $<0.05$ were considered significant.

\section{RESULTS}

P15 rats. Mortality was 9\% in the atropine group; 5\%, 7\% or $10 \%$ in the topiramate 20,40 , or 70 min groups, and $5 \%$, $8 \%$, or $6 \%$ in the diazepam groups, respectively. We did not see any tonic seizures. On the first day, all rats with SE lost weight $(-0.03 \pm 0.6 \mathrm{~g})$, whereas "no SE" animals gained weight $(1.6 \pm 0.1 \mathrm{~g})$. During the next three days, rats subjected to SE gained less weight than the "no SE" animals $(1.6 \pm 0.2 \mathrm{~g}$ vs. $3.1 \pm 0.2 \mathrm{~g})$. One week after SE, experimental animals did not differ significantly from "no SE" controls.

Course of $S E$ in atropine controls. Immediately after pilocarpine injection, pups developed tremor, the first epileptiform spikes appeared after $6.1 \pm 1.5 \mathrm{~min}$., and the first EEG seizure appeared after $8.2 \pm 1.7 \mathrm{~min}$. Behavioral seizure manifestations varied from tremor and/or head bobbing to head and forelimbs clonus, occasionally with running seizures. Continuous polyspike activity was replaced approximately 50 min after atropine injection by periodic epileptiform discharges. Cumulative seizure time was $141.8 \pm 31.0 \mathrm{~min}$ after atropine injection. The "no SE" pups did not seize and mean spike frequency was $2.1 \pm 0.3$ spikes $/ \mathrm{h}$.

Effect of treatment on course of SE. The 10 or $50 \mathrm{mg} / \mathrm{kg}$ doses of topiramate did not suppress behavioral seizures, did not shorten continuous polyspike activity, and did not reduce total seizure time, cumulative seizure time, the number of seizures, duration of SE, or spike frequency when compared with the atropine group (Table 1; Fig. 1A,B and data not shown).

Treatment with $5 \mathrm{mg} / \mathrm{kg}$ of diazepam suppressed behavioral seizures promptly, shortened continuous polyspike activity, reduced cumulative seizure time and total seizure time, duration of SE and number of seizures at all time points tested (Table 1; Fig. 1A,B).

Effect of treatment on epileptogenesis. When tested 3 mo after SE, 75\% of the atropine animals displayed SRS with a mean behavioral seizure score of $1.6 \pm 0.3$. The average seizure frequency was $1.4 \pm 1.1$ seizures/d with mean seizure duration of $12.8 \pm 4.9 \mathrm{~s}$.

Early treatment with topiramate $(10 \mathrm{mg} / \mathrm{kg}$ ) (at 20 or 40 min) completely protected, and late treatment (at $70 \mathrm{~min}$ ) partially protected against development of SRS (1/7 rats had 1 isolated nonconvulsive seizure) (Table 2, Fig. 2A,B). Topiramate also significantly reduced spike frequency in comparison to the atropine group (Table 2).

Topiramate at a higher dose $(50 \mathrm{mg} / \mathrm{kg})$ did not prevent development of epilepsy at any time point tested, although it reduced the frequency of SRS two- to seven-fold (data not shown).

Even though diazepam was very effective against acute SE, it only had a modest effect on epileptogenesis (Fig. 2A). Diazepam significantly altered the incidence of SRS when treated at $20 \mathrm{~min}$, and there was a non-significant trend with a reduction of seizure frequency in the other two groups (40, 70 min; Fig. 2B).

P28 rats. Mortality was $90 \%$ in the atropine group, $70 \%$, $60 \%$ and $50 \%$ in the groups treated with topiramate at $70 \mathrm{~min}$, $40 \mathrm{~min}$ and $20 \mathrm{~min}$, respectively, and $10 \%, 13 \%$, and $20 \%$ in the 20,40 or 70 min diazepam groups. On average, death occurred within $103.3 \pm 3.5$ min after pilocarpine and was 
Table 1. Acute parameters describing the severity of lithium/pilocarpine SE in P15 and P28 rats

\begin{tabular}{|c|c|c|c|c|c|c|c|c|}
\hline & & $\begin{array}{l}\text { Latency to seizure } \\
\text { interruption (min } \\
\text { after treatment) }\end{array}$ & $\begin{array}{c}\text { Cumulative } \\
\text { seizure } \\
\text { time (min } \\
\text { after treatment) }\end{array}$ & $\begin{array}{c}\text { Number of } \\
\text { seizures }\end{array}$ & $\begin{array}{l}\text { Duration of } \\
\text { SE (min after } \\
\text { onset of SE) }\end{array}$ & $\begin{array}{c}\text { Total } \\
\text { seizure time } \\
\text { (min after } \\
\text { onset of SE) }\end{array}$ & $\begin{array}{c}\text { Spike } \\
\text { frequency } \\
\text { (spikes/h) }\end{array}$ & $\mathrm{N}$ \\
\hline \multicolumn{9}{|l|}{ P15 } \\
\hline Atropine $(10 \mathrm{mg} / \mathrm{kg})$ & $70 \mathrm{~min}$ & $52.7 \pm 16.0$ & $141.8 \pm 31.0$ & $78.1 \pm 23.1$ & $1057.0 \pm 71.6$ & $196.2 \pm 30.5$ & $13.0 \pm 5.3$ & 10 \\
\hline \multirow[t]{2}{*}{ Topiramate $(10 \mathrm{mg} / \mathrm{kg})+$ atropine } & $20 \min$ & $74.6 \pm 16.8$ & $136.7 \pm 34.7$ & $49.3 \pm 11.8$ & $826.6 \pm 197.7$ & $151.7 \pm 34.5$ & $11.8 \pm 3.1$ & 7 \\
\hline & $40 \mathrm{~min}$ & $47.4 \pm 17.5$ & $95.7 \pm 29.1$ & $37.3 \pm 10.2$ & $811.6 \pm 223.6$ & $130.7 \pm 29.4$ & $15.6 \pm 3.1$ & 7 \\
\hline \multirow{2}{*}{ Diazepam $(5 \mathrm{mg} / \mathrm{kg})+$ atropine } & $40 \mathrm{~min}$ & $12.7 \pm 1.5^{*}$ & $12.7 \pm 1.5^{*}$ & $1 \pm 0^{*}$ & $12.7 \pm 1.5^{*}$ & $47.7 \pm 1.4^{*}$ & $18.1 \pm 8.2$ & 5 \\
\hline & $70 \mathrm{~min}$ & $10.7 \pm 1.4^{*}$ & $11.1 \pm 1.6^{*}$ & $1.4 \pm 0.3^{*}$ & $248.1 \pm 114.8^{*}$ & $76.2 \pm 1.5^{*}$ & $15.2 \pm 5.4$ & 7 \\
\hline \multicolumn{9}{|l|}{$\mathrm{P} 28$} \\
\hline Atropine $(10 \mathrm{mg} / \mathrm{kg})$ & $70 \min$ & $185.7 \pm 21.1$ & $211.7 \pm 21.3$ & $65.4 \pm 19.3$ & $1087.7 \pm 86.2$ & $268.0 \pm 20.6$ & $134.3 \pm 13.3$ & 6 \\
\hline \multirow[t]{2}{*}{ Topiramate $(10 \mathrm{mg} / \mathrm{kg})+$ atropine } & $20 \mathrm{~min}$ & $29.7 \pm 11.3^{*}$ & $33.3 \pm 15.0 *$ & $2.7 \pm 1.7 *$ & $357.0 \pm 338.5$ & $40.0 \pm 14.1^{*}$ & $10.7 \pm 4.3^{*}$ & 5 \\
\hline & $40 \mathrm{~min}$ & $45.3 \pm 21.5^{*}$ & $55.3 \pm 20.0 *$ & $9.3 \pm 7.4 *$ & $414.0 \pm 345.2$ & $80.8 \pm 19.1^{*}$ & $10.8 \pm 1.6^{*}$ & 5 \\
\hline
\end{tabular}

Parameters of the severity of lithium/pilocarpine SE in P15 or P28 rats were measured over 24 hours of continuous video-EEG recording using Harmonie Software: latency to seizure interruption (timed from the end of the topiramate, diazepam and/or atropine injection when continuous polyspike or spike and wave activity was interrupted for at least $1 \mathrm{~min}$ ), cumulative seizure time (timed from the topiramate, diazepam and/or atropine injection, subtracting interictal time), number of seizures, duration of SE (time from the onset of SE to the end of the last seizure, including interictal time), total seizure time (total time spent in seizures, timed from the onset of SE, subtracting interictal time), and spike frequency (spikes per hour).

$N=$ number of animals $* p<0.05$ versus atropine controls. Values are means \pm SEM.

A.

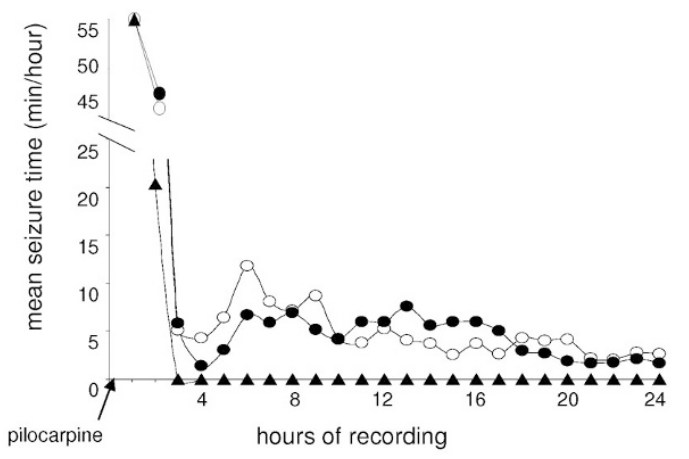

B.

25 min after treatment

2 hours after treatment

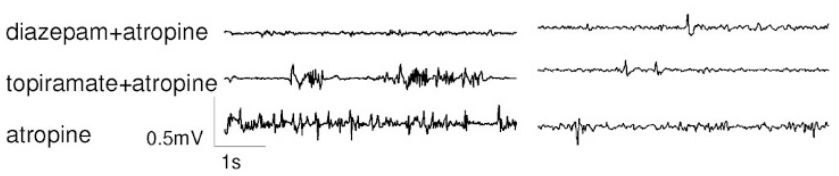

Figure 1. Effect of topiramate $(10 \mathrm{mg} / \mathrm{kg}$ ) or diazepam treatment (given 70 min after pilocarpine) on severity of lithium/pilocarpine SE in P15 rats. (A) Time-course of topiramate, diazepam and/or atropine effects on seizure activity (seizure time subtracting interictal time) atropine $(\mathbf{O})$; topiramate + atropine $(\bigcirc)$; diazepam + atropine $(\boldsymbol{\Delta})(B)$ Representative EEG recorded from skull electrodes in P15 rats, taken $25 \mathrm{~min}$ and $2 \mathrm{~h}$ after topiramate, diazepam and/or atropine injection. Values are means.

always preceded by tonic extension. The increased susceptibility of rats to pilocarpine around third week of life has been previously reported (23). The mortality rate was not dependent on the topiramate dose, in contrast to a previous report (24). During the three days after SE, extra feeding and hydration were necessary. On the first day after SE, atropine controls as well as treated animals, lost weight $(-4.4 \pm 3.9 \mathrm{~g})$, whereas "no SE" animals gained weight $(5.0 \pm 0.4 \mathrm{~g})$. The next day, SE animals gained weight $(6.6 \pm 2.6 \mathrm{~g})$, and on the third day after SE, they became comparable with "no SE" animals.

Course of SE in atropine controls. Pilocarpine induced the first spikes in $5.2 \pm 2.3 \mathrm{~min}$, the first discrete seizure after 8.2 $\pm 2.1 \mathrm{~min}$, and continuous polyspike activity after $15.5 \pm 2.5$ min. Pups developed head and forelimbs clonus, with rearing and falling accompanied by high frequency spikes (10-13 $\mathrm{Hz}$ ). By approximately $2 \mathrm{~h}$ after atropine, the animals displayed less severe seizure behavior (head bobbing, twitching of vibrissae, facial myoclonus), accompanied by spike-andwave complexes of decreasing frequency and amplitude. Continuous polyspike activity was replaced after $185.7 \pm 21.1$ min by multiple intermittent seizures $65.4 \pm 19.3$ during $24 \mathrm{~h}$ of continuous recording with head and forelimb clonus as motor correlates. Cumulative seizure time was $211.7 \pm 21.3$ min. The "no SE" animals did not develop SE and had a mean spike frequency of $3.6 \pm 0.7$ spikes/h.

Effect of treatment on course of SE. Topiramate (10 $\mathrm{mg} / \mathrm{kg}$ ) attenuated both behavioral and electrographic expression of SE in a time-dependent manner. It also reduced latency to seizure interruption, cumulative seizure time, total seizure time and spike frequency in comparison to the atropine controls (Table 1, Fig. 3A) at all time points tested. Only early treatment ( 20 or $40 \mathrm{~min}$ ) decreased the number of seizures. Late seizures persisted, so the duration of SE did not change (Table 1). The latency to seizure interruption was highly dependent on the time of topiramate treatment (Fig. 3B).

Diazepam suppressed behavioral seizures, shortened continuous polyspike activity and reduced cumulative seizure time at all time points tested (Table 1). 
Table 2. Chronic parameters describing the severity of epilepsy three months later

\begin{tabular}{|c|c|c|c|c|c|c|c|c|}
\hline & & $\begin{array}{c}\% \text { of } \\
\text { animals } \\
\text { with SRS }\end{array}$ & $\begin{array}{c}\% \text { of } \\
\text { animals with } \\
\text { convulsive SRS }\end{array}$ & $\begin{array}{l}\text { Number of } \\
\text { SRS/week }\end{array}$ & $\begin{array}{l}\text { Mean seizure } \\
\text { duration (sec) }\end{array}$ & $\begin{array}{c}\text { Spike } \\
\text { frequency } \\
\text { (spikes } / \mathrm{h} \text { ) }\end{array}$ & $\begin{array}{c}\text { Behavioral } \\
\text { seizure } \\
\text { score }\end{array}$ & $\mathrm{N}$ \\
\hline \multicolumn{9}{|l|}{$\mathrm{P} 15$} \\
\hline Atropine $(10 \mathrm{mg} / \mathrm{kg})$ & $70 \mathrm{~min}$ & $75 \%$ & $25 \%$ & $10.1 \pm 6.9$ & $12.8 \pm 4.9$ & $40.8 \pm 10.8$ & $1.6 \pm 0.3$ & 8 \\
\hline \multirow[t]{3}{*}{ Topiramate $(10 \mathrm{mg} / \mathrm{kg})+$ atropine } & $20 \mathrm{~min}$ & 0 & $\mathrm{n} / \mathrm{a}$ & $0 *$ & $\mathrm{n} / \mathrm{a}$ & $14.4 \pm 3.5^{*}$ & $\mathrm{n} / \mathrm{a}$ & 6 \\
\hline & $40 \mathrm{~min}$ & 0 & $\mathrm{n} / \mathrm{a}$ & $0 *$ & $\mathrm{n} / \mathrm{a}$ & $20.2 \pm 4.7^{*}$ & $\mathrm{n} / \mathrm{a}$ & 7 \\
\hline & $70 \mathrm{~min}$ & $14 \% *$ & 0 & $0.1 \pm 0.1 *$ & $\mathrm{n} / \mathrm{a}$ & $16.7 \pm 4.2^{*}$ & $\mathrm{n} / \mathrm{a}$ & 7 \\
\hline \multirow[t]{3}{*}{ Diazepam $(5 \mathrm{mg} / \mathrm{kg})+$ atropine } & $20 \min$ & $17 \% *$ & 0 & $0.2 \pm 0.2 *$ & $\mathrm{n} / \mathrm{a}$ & $16.8 \pm 2.0^{*}$ & $\mathrm{n} / \mathrm{a}$ & 6 \\
\hline & $40 \mathrm{~min}$ & $33 \%$ & $17 \%$ & $1.6 \pm 0.7$ & $12.1 \pm 9.2$ & $19.4 \pm 4.0^{*}$ & $1.5 \pm 1.5$ & 6 \\
\hline & $70 \mathrm{~min}$ & $50 \%$ & $17 \%$ & $1.2 \pm 0.5$ & $10.2 \pm 5.2$ & $21.2 \pm 5.8^{*}$ & $1.8 \pm 1.1$ & 6 \\
\hline \multicolumn{9}{|l|}{ P28 } \\
\hline Atropine $(10 \mathrm{mg} / \mathrm{kg})$ & $70 \mathrm{~min}$ & $92 \%$ & $69 \%$ & $123.1 \pm 35.5$ & $26.9 \pm 7.3$ & $104.3 \pm 26.1$ & $2.8 \pm 0.6$ & 13 \\
\hline \multirow[t]{3}{*}{ topiramate $(10 \mathrm{mg} / \mathrm{kg})+$ atropine } & $20 \mathrm{~min}$ & $17 \% *$ & 0 & $0.2 \pm 0.2 *$ & $\mathrm{n} / \mathrm{a}$ & $20.8 \pm 2.1^{*}$ & $\mathrm{n} / \mathrm{a}$ & 6 \\
\hline & $40 \mathrm{~min}$ & $71 \%$ & $29 \%$ & $21.9 \pm 9.8 *$ & $33.5 \pm 4.6$ & $137.3 \pm 48.2$ & $1.9 \pm 0.7$ & 7 \\
\hline & $70 \mathrm{~min}$ & $88 \%$ & $63 \%$ & $28.6 \pm 12.2 *$ & $37.5 \pm 2.0$ & $79.7 \pm 25.2$ & $2.2 \pm 0.5$ & 8 \\
\hline \multirow[t]{3}{*}{ Diazepam $(5 \mathrm{mg} / \mathrm{kg})+$ atropine } & $20 \mathrm{~min}$ & $17 \% *$ & $16 \%$ & $1.3 \pm 1.3 *$ & $\mathrm{n} / \mathrm{a}$ & $35.0 \pm 2.1^{*}$ & $\mathrm{n} / \mathrm{a}$ & 6 \\
\hline & $40 \mathrm{~min}$ & $67 \%$ & $33 \%$ & $15.0 \pm 4.2 *$ & $32.3 \pm 14.5$ & $100.0 \pm 20.0$ & $1.3 \pm 0.7$ & 6 \\
\hline & $70 \mathrm{~min}$ & $100 \%$ & $30 \%$ & $19.6 \pm 5.8 *$ & $25.5 \pm 6.6$ & $150.2 \pm 50.2$ & $1.7 \pm 0.6$ & 10 \\
\hline
\end{tabular}

Parameters of the severity of epileptogenesis were measured over one week of continuous video-EEG recording using Harmonie Software.

Incidence of SRS (spontaneous recurrent seizures), incidence of convulsive SRS (score 3-5), the number of SRS per week, mean seizure duration, spike frequency (spikes /hour) and mean behavioral seizure score.

$N$, number of animals; $* P<0.05$ versus atropine controls. Values are means \pm SEM.

A.

Acute outcome Cumulative seizure time

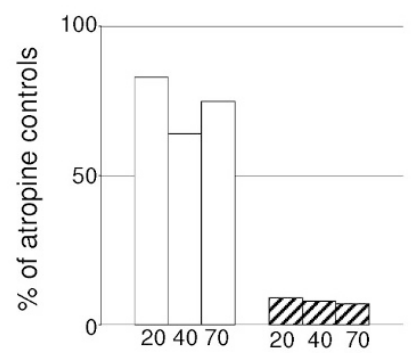

B.

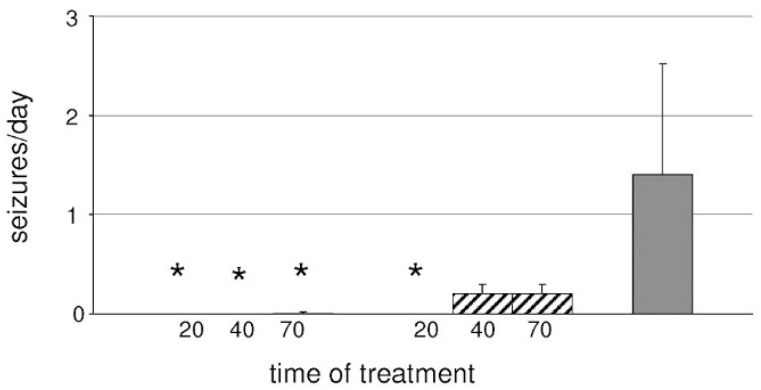

Figure 2. (A) Acute vs. chronic outcome of acute topiramate $(10 \mathrm{mg} / \mathrm{kg})$ or diazepam treatment given 20,40 or 70 min after pilocarpine in P15 rats. Topiramate did not reduce cumulative seizure time, but blocked development of SRS. Diazepam reduced cumulative seizure time and did not prevent development of SRS, atropine ( $\square$ ); topiramate+atropine ( $\square$ ); diazepam+atropine $(\mathbb{Z})$. (B) Just early treatment with diazepam (20 min) reduced frequency of SRS. ${ }^{*} p<0.05$ vs. atropine controls. Values are means \pm SEM $20(n=6), 40(n=7), 70(n=7)$ topiramate, $20(n=6), 40$ $(n=6), 70(n=6)$ min diazepam, atropine $(n=8)$.

Effect of treatment on epileptogenesis. When recorded 3 mo later, $92 \%$ of atropine control animals had developed SRS with mean behavioral seizure severity $2.8 \pm 0.6$, and $69 \%$ of animals developed convulsive seizures (stage 3-5). The aver-
A.

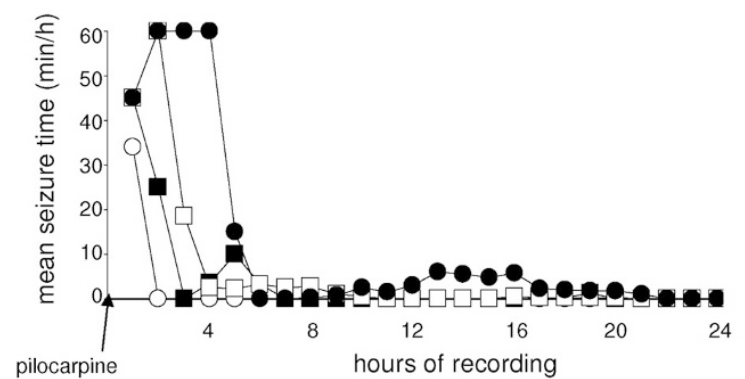

B.

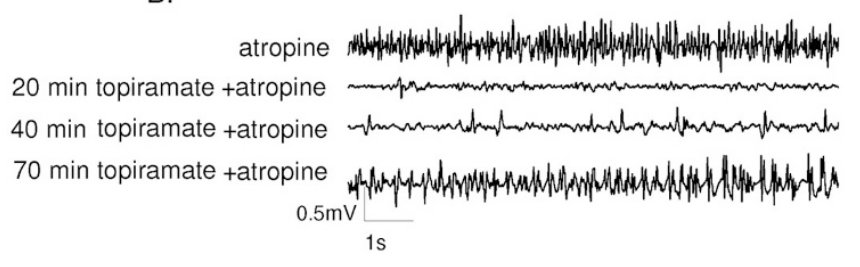

Figure 3. Effect of topiramate $(10 \mathrm{mg} / \mathrm{kg})$ treatment given 20,40 or $70 \mathrm{~min}$ after pilocarpine on severity of lithium/pilocarpine SE in P28 rats. (A) Time-dependent effect of topiramate treatment $(10 \mathrm{mg} / \mathrm{kg}$ ) given 20,40 or 70 min after pilocarpine on seizure activity of SE in P28 rats, atropine (-); 20 min topiramate +atropine $(\bigcirc)$; 40 min topiramate +atropine $(\square)$; 70 min topiramate +atropine (ם). (B) Representative EEG recordings taken 90 min after topiramate and/or atropine treatment. Continuous polyspike activity persisted in $70 \mathrm{~min}$ topiramate animal and atropine control, while single spike activity appeared in 20 or 40 min topiramate animals. Values are means.

age seizure frequency was $17.5 \pm 5.1$ seizures/d with mean individual seizure duration of $26.9 \pm 7.3 \mathrm{~s}$.

Early treatment with topiramate $(10 \mathrm{mg} / \mathrm{kg})$ or diazepam $(5$ $\mathrm{mg} / \mathrm{kg}$ ) reduced seizure frequency (Table 2, Fig. 4B) and significantly reduced the incidence of chronic epilepsy (Table 2): $17 \%$ in both groups vs. $92 \%$ in atropine controls. Late treatment (40 and $70 \mathrm{~min}$ ) did not alter the incidence of chronic recurrent seizures, but decreased their frequency (Ta- 
A.

Acute outcome Cumulative seizure time
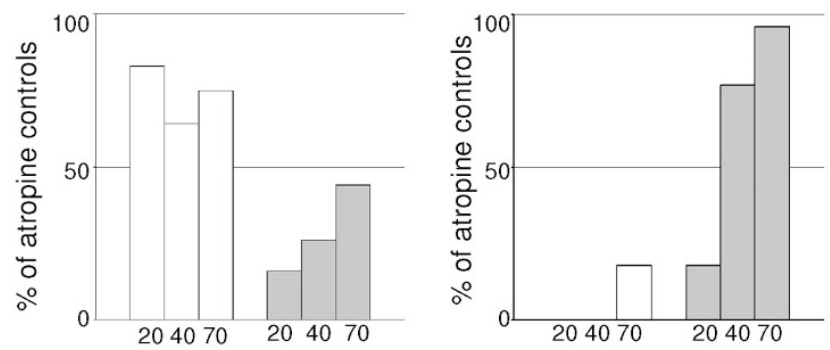

B.

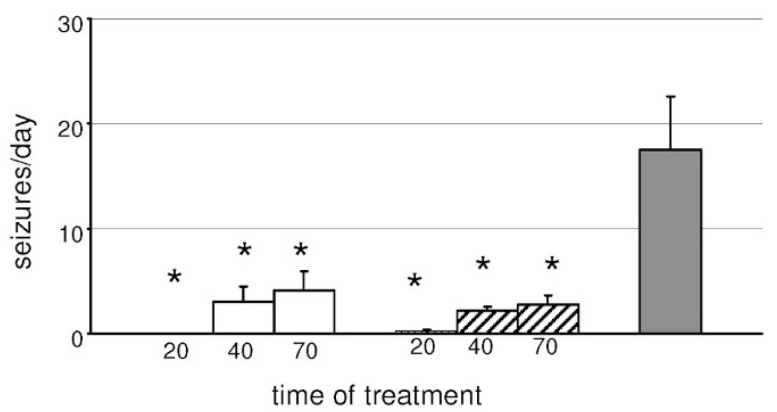

Figure 4. (A) Acute vs. chronic outcome of acute topiramate $(10 \mathrm{mg} / \mathrm{kg})$ treatment given 20, 40 or 70 min after pilocarpine in P15 or in P28 rats. Topiramate was a better anticonvulsant when given to P28 rats; topiramate was antiepileptogenic in P15 rats, $(B)$ Effect of topiramate $(10 \mathrm{mg} / \mathrm{kg})$ or diazepam treatment during SE in P28 rats on epileptogenesis, evaluated 3 mo later. Early treatment $(20 \mathrm{~min})$ partially protected against development of SRS and significantly reduced the frequency of SRS. Late treatment (40 or $70 \mathrm{~min}$ ) reduced the frequency of SRS (disease-modifying effect). $* p<0.05$ vs. atropine controls. Values are means \pm SEM. Topiramate + atropine P15 ( $\square$ ); topiramate +atropine P28 $(\square)$; diazepam + atropine P28 ( $)$; atropine P28 ( $\square) .20(n=6), 40(n=7), 70(n=8)$ topiramate, $20(n=6), 40(n=6)$, $70(n=10)$ min diazepam, atropine $(n=13)$.

ble 2, Fig. 4B). Topiramate was more effective in reducing the severity of acute SE in P28 rats when compared with P15 rats, but reduction of SRS was much greater in the younger group (Fig. 4A).

High-dose topiramate $(50 \mathrm{mg} / \mathrm{kg})$ did not prevent development of epilepsy at any time points tested (data not shown), although there was a nonsignificant 3- to 4-fold reduction of seizure frequency.

\section{DISCUSSION}

This study demonstrates that the anticonvulsant and antiepileptogenic properties of a drug can be dissociated, and that the extent of this dissociation can vary with the degree of brain maturation. It also suggests that some new generation anticonvulsants may have antiepileptogenic potential, and that a comparative evaluation in humans is imperative. Further it confirms the strong relationship between duration of SE and long-term consequences.

A comparison of the effects of topiramate vs. diazepam in the P15 rats suggests a dissociation between anticonvulsant and antiepileptogenic effects of acute treatment of SE: topira- mate had no effect on the duration or severity of SE (mean latency to seizure cessation of three groups was $113 \mathrm{~min}$ vs. 141 in atropine controls), while diazepam reduced the latency to seizure cessation in the three groups to $13 \mathrm{~min}$ on average. In spite of this nine-fold reduction of mean latency to seizure cessation (13 vs. $113 \mathrm{~min}$ ) by diazepam, $17 \%$ of rats in the 20 min group, 33\% treated at $40 \mathrm{~min}$ and $50 \%$ treated at $70 \mathrm{~min}$ developed SRS, which contrasts with the development of SRS in only 1 of 20 rats in the topiramate-treated group. In the 40 min group, the topiramate-treated animals averaged $130 \mathrm{~min}$ of total seizure time but none developed SRS, while the diazepam rats experienced only $47 \mathrm{~min}$ of SE, and $33 \%$ of them developed SRS. A comparison of topiramate effects at two different ages supports that same conclusion: topiramate was a more effective anticonvulsant in P28 than in P15 rats, reducing mean latency to seizure cessation to $60 \mathrm{~min}$ vs. 212 min in atropine controls, but $17 \%$ of rats in the 20 min group, $71 \%$ in the 40 min group and $88 \%$ in 70 min group developed SRS.

A limitation of our study is that we did not manage pharmacokinetic variables, and our conclusions pertaining to antiepileptogenic effects are based on acute treatment with a single dose of the test drug. Continuous treatment with topiramate for several weeks after initial dose may produce different results.

We are not aware of any other study showing dissociation of anticonvulsant from antiepileptogenic effects in SE models in immature animals. However, Koh showed, in a hypoxiainduced seizure model in P10 rats, that topiramate exerted antiepileptogenic action when administered shortly following seizures (25). In adult rats, Prasad (18) showed that MK-801 had a modest effect on SE when compared with phenobarbital, but had a slightly wider window for the prevention of epilepsy. Fujikawa (26) showed that ketamine failed to stop seizures but was neuroprotective when administered after the onset of SE. In vitro, Khalilov showed that in the intact neonatal rat hippocampus, blockade of NMDA receptors does not block seizures but efficiently prevents the epileptogenic process (27).

At P28, early treatment with topiramate as well as diazepam partially protected the brain from development of SRS and later treatment had a disease-modifying effect, i.e., reduced the severity of epilepsy. The beneficial effects of topiramate treatment might have resulted in part, from the reduction in severity of SE or may be representative of bias introduced by the high mortality. The efficacy of topiramate treatment declined as the duration of SE increased. This is a phenomenon that has been reported with other anticonvulsants as well $(18,28)$.

Paradoxically, the lower dose topiramate $(10 \mathrm{mg} / \mathrm{kg})$ was more effective in preventing of development of SRS than the higher dose $(50 \mathrm{mg} / \mathrm{kg})$. We chose these two doses based on our preliminary studies (unpublished data) and previous data, which showed that doses higher than $50-60 \mathrm{mg} / \mathrm{kg}$ did not offer additional protection from any of the acute or chronic consequences of SE, and on the anticonvulsant ED50 in several seizure models $(24,29)$. Reduction of anticonvulsive as well neuroprotective effect with increasing dose has been reported previously $(24,30,31)$. 
There are only a limited number of reports showing the effect of topiramate in immature animals. One showed that topiramate given for $4 \mathrm{wk}$ following a series of neonatal seizures or lithium/pilocarpine SE induced in P20 pups improved cognitive function after SE model only, and had no effect on histologic damage (32). In other studies, pretreatment with topiramate $30 \mathrm{~min}$ before or repeated doses given for 48 $\mathrm{h}$ after hypoxia-ischemia in P10 pups prevented the increase in susceptibility to kainate induced seizures and hippocampal injury later $(25,31)$.

In mature animals, diazepam given $2 \mathrm{~h}$ after the onset of $\mathrm{SE}$ was able to reduce the occurrence and severity of later seizures. The dose of diazepam used in those studies was much higher $(4 \times)$ than the dose used in our study which produced an effective anticonvulsant effect (19). Diazepam as well as other antiepileptic drugs can trigger apoptotic neurodegeneration in immature animals younger than those used in the present study (33). On the other hand, Glier recently reported that topiramate $(40 \mathrm{mg} / \mathrm{kg})$ had no such effect when given to P14 rats (34).

It is not clear whether the antiepileptogenic or diseasemodifying properties of topiramate in immature rats are related to its neuroprotective effect. In experimental models of stroke, topiramate reduced infarct volume (35) and CA1 damage (36). Acute treatment with topiramate in different models of SE reduced acute damage in CA1, CA3 and the hilus (24, 9). Topiramate given for one week after lithium/pilocarpine SE reduced damage in CA1 and CA3 without any effect on epileptogenesis (24), as reported also for other agents $(37,38)$.

The neuroprotective mechanism of topiramate is not completely understood. The mechanism potentially includes: inhibition of voltage- gated calcium channels (N-, P-, and Rtype calcium channels), effect on GluR5 kainate receptormediated synaptic current, antagonistic action at AMPA-R mediated responses, blockade of voltage-gated sodium channels, potentiation of GABAergic signaling, and inhibition of carbonic anhydrase, particularly isozymes II and IV (39). The differential antiepileptogenic effect of topiramate on P15 and P28 rats may be related to the importance of calciumpermeant AMPA receptors in the younger animals (40). The ontogeny of GluR2 subunit expression in the CA1 subfield of the hippocampus is associated with reduced calcium permeability as the brain matures (40). This may mean that the AMPA antagonism of topiramate may be more important in the epileptogenic process in P15 animals.

The dissociation between anticonvulsive and antiepileptogenic effects at specific stages of development suggests that a systematic study of the antiepileptogenic properties of all anticonvulsant drugs is needed to guide future clinical studies. It also suggests that the treatment of SE might benefit from polytherapy where the anticonvulsive efficacy of one drug would be complemented by the antiepileptogenic efficacy of another.

Acknowledgments. We are grateful to Richard Shank, Ph.D., and to Steve White, Ph.D., for their suggestions and comments.

\section{REFERENCES}

1. DeLorenzo RJ, Hauser WA, Towne AR, Boggs JG, Pellock JM, Penberthy L, Garnett L, Fortner CA, Ko D 1996 A prospective, population-based epidemiologic study of status epilepticus in Richmond, Virginia. Neurology 46:1029-1035

2. DeLorenzo RJ, Towne AR, Pellock JM, Ko D 1992 Status epilepticus in children, adults, and the elderly. Epilepsia 33:S15-S25

3. Maytal J, Shinnar S, Moshe SL, Alvarez LA 1989 Low morbidity and mortality of status epilepticus in children. Pediatrics 83:323-331

4. Hesdorffer DC, Logroscino G, Cascino G, Annegers JF, Hauser WA 1998 Risk of unprovoked seizure after acute symptomatic seizure: effect of status epilepticus. Ann Neurol 44:908-912

5. Sankar R, Shin DH, Liu H, Mazarati A, Pereira de Vasconcelos A, Wasterlain CG 1998 Patterns of status epilepticus-induced neuronal injury during development and long-term consequences. J Neurosci 18:8382-8393

6. Sankar R, Shin D, Mazarati AM, Liu H, Katsumori H, Lezama R, Wasterlain CG 2000 Epileptogenesis after status epilepticus reflects age- and model-dependent plasticity. Ann Neurol 48:580-589

7. Roch C, Leroy C, Nehlig A, Namer IJ 2002 Predictive value of cortical injury for the development of temporal lobe epilepsy in 21-day-old rats: an MRI approach using the lithium-pilocarpine model. Epilepsia 43:1129-1136

8. Kubova H, Mares P, Suchomelova L, Brozek G, Druga R, Pitkanen A 2004 Status epilepticus in immature rats leads to behavioural and cognitive impairment and epileptogenesis. Eur J Neurosci 19:3255-3265

9. Baram TZ, Dube CM, Chung G, Akhtar F 2004 Prolonged experimental febrile seizures in immature rats cause spontaneous behavioral and electrophysiological seizures during adulthood. Epilepsia 45:6

10. Sankar R, Rho JM 2004 Ontogeny of Molecular Targets of Antiepileptic Drugs: Impact on Drug Choice. In: Rho JM, Sankar R, Cavazos JE (eds) Epilepsy: Scientific Foundations of Clinical Practice. M Dekker, New York, pp 61-76

11. Temkin NR, Dikmen SS, Wilensky AJ, Keihm J, Chabal S, Winn HR 1990 A randomized, double-blind study of phenytoin for the prevention of post-traumatic seizures. N Engl J Med 323:497-502

12. Temkin NR, Dikmen SS, Anderson GD, Wilensky AJ, Holmes MD, Cohen W, Newell DW, Nelson P, Awan A, Winn HR 1999 Valproate therapy for prevention of posttraumatic seizures: a randomized trial. J Neurosurg 91:593-600

13. Sasa M, Yan H, Nagayama T, Serikawa T 2003 Anti-epileptogenic properties of levetiracetam in the spontaneously epileptic rat (SER). Epilepsia 44:175

14. Mikati MA, Holmes GL, Chronopoulos A, Hyde P, Thurber S, Gatt A, Liu Z, Werner S, Stafstrom CE 1994 Phenobarbital modifies seizure-related brain injury in the developing brain. Ann Neurol 36:425-433

15. Capella HM, Lemos T 2002 Effect on epileptogenesis of carbamazepine treatment during the silent period of the pilocarpine model of epilepsy. Epilepsia 43:110-111

16. Mazarati AM, Sofia RD, Wasterlain CG 2002 Anticonvulsant and antiepileptogenic effects of fluorofelbamate in experimental status epilepticus. Seizure 11:423-430

17. Mazarati A, Bragin A, Baldwin R, Shin D, Wilson C, Sankar R, Naylor D, Engel J, Wasterlain CG 2002 Epileptogenesis after self-sustaining status epilepticus. Epilepsia 43:74-80

18. Prasad A, Williamson JM, Bertram EH 2002 Phenobarbital and MK-801, but not phenytoin, improve the long-term outcome of status epilepticus. Ann Neurol 51:175-181

19. Pitkanen A, Kharatishvili I, Narkilahti S, Lukasiuk K, Nissinen J 2005 Administration of diazepam during status epilepticus reduces development and severity of epilepsy in rat. Epilepsy Res 63:27-42

20. Gottlieb A, Keydar I, Epstein HT 1977 Rodent brain growth stages: an analytical review. Biol Neonate 32:166-176

21. Haas KZ, Sperber EF, Moshe SL 1990 Kindling in developing animals: expression of severe seizures an enhanced development of bilateral foci. Brain Res Dev Brain Res 56:275-280

22. Racine R 1972 Modification of seizure activity by electrical stimulation. II. Motor seizure. Electroencephalogr Clin Neurophysiol 32:281-294

23. Priel MR dos SantosNF, Cavalheiro EA 1996 Developmental aspects of the pilocarpine model of epilepsy. Epilepsy Res 26:115-121

24. Rigoulot MA, Koning E, Ferrandon A, Nehlig A 2003 Neuroprotective properties of topiramate in the lithium- pilocarpine model of epilepsy. J Pharmacol Exp Ther 308:787-795

25. Koh S, Tibayan FD, Simpson JN, Jensen FE 2004 NBQX or topiramate treatment after perinatal hypoxia-induced seizures prevents later increases in seizure-induced neuronal injury. Epilepsia 45:569-575

26. Fujikawa DG 1995 Neuroprotective effect of ketamine administered after status epilepticus onset. Epilepsia 36:186-195

27. Khalilov I, Holmes GL, Ben-Ari Y 2003 In vitro formation of a secondary epileptogenic mirror focus by interhippocampal propagation of seizures. Nat Neurosci 6:1079-1085

28. Walton NY, Treiman DM 1988 Response of status epilepticus induced by lithium and pilocarpine to treatment with diazepam. Exp Neurol 101:267-275

29. Niebauer M, Gruenthal M 1999 Topiramate reduces neuronal injury after experimental status epilepticus. Brain Res 837:263-269

30. White HS, Brown SD, Woodhead JH, Skeen GA, Wolf HH 1997 Topiramate enhances GABA-mediated chloride flux and GABA-evoked chloride currents in murine brain neurons and increases seizure threshold. Epilepsy Res 28:167-179

31. Koh S, Jensen FE 2001 Topiramate blocks perinatal hypoxia-induced seizures in rat pups. Ann Neurol 50:366-372

32. Cha BH, Silveira DC, Liu X, Hu Y, Holmes GL 2002 Effect of topiramate 
following recurrent and prolonged seizures during early development. Epilepsy Res 51:217-232

33. Bittigau P, Sifringer M, Genz K, Reith E, Pospischil D, Govindarajalu S, Dzietko M, Pesditschek S, Mai I, Dikranian K, Olney JW, Ikonomidou C 2002 Antiepileptic drugs and apoptotic neurodegeneration in the developing brain. Proc Natl Acad Sci 99:15089-15094

34. Glier C, Dzietko M, Bittigau P, Jarosz B, Korobowicz E, Ikonomidou C 2004 Therapeutic doses of topiramate are not toxic to the developing rat brain. Exp Neurol 187:403-409

35. Yang Y, Shuaib A, Li Q, Siddiqui MM 1998 Neuroprotection by delayed administration of topiramate in a rat model of middle cerebral artery embolization. Brain Res 804:169-176

36. Edmonds HL Jr.Jiang, YD, Zhang PY, Shank R 2001 Topiramate as a neuroprotectant in a rat model of global ischemia-induced neurodegeneration. Life Sci 69:2265-2277
37. Andre V, Ferrandon A, Marescaux C, Nehlig A 2001 Vigabatrin protects against hippocampal damage but is not antiepileptogenic in the lithium-pilocarpine model of temporal lobe epilepsy. Epilepsy Res 47:99-117

38. Brandt C, Potschka H, Loscher W, Ebert U 2004 N-methyl-D-aspartate receptor blockade after status epilepticus protects against limbic brain damage but not against epilepsy in the kainate model of temporal lobe epilepsy. Neuroscience 118:727-740

39. Sankar R, Holmes GL 2004 Mechanisms of action for the commonly used antiepileptic drugs: relevance to antiepileptic drug-associated neurobehavioral adverse effects. J Child Neurol 19:S6-S14

40. Sanchez RM, Koh S, Rio C, Wang C, Lamperti ED, Sharma D, Corfas G, Jensen FE 2001 Decreased glutamate receptor 2 expression and enhanced epileptogenesis in immature rat hippocampus after perinatal hypoxia-induced seizures. J Neurosci 21:8154-8163 